\title{
Normal vs. reverse fault - the example of curvature's usage on gravimetric data
}

\author{
Roland KARCOL* (D), Roman PAŠTEKA (D) \\ Department of Applied and Environmental Geophysics, Comenius University, \\ Mlynská dolina, PriF UK, Ilkovičova 6, 84215 Bratislava, Slovak Republic \\ e-mail: roland.karcol@uniba.sk, roman.pasteka@uniba.sk
}

\begin{abstract}
The gravitational effects caused by normal and reverse faults are very close to each other, both in amplitude and in the shape. We demonstrate the usage of the first curvature as a tool for the setting the slope orientation without the additional geological information. The curvature is calculated not only for the measured data, but for their upward continuation, too. This step helps to lower instability of the curvature computation and is important in the interpretation of the resultant curvature as well. We applied this method on the synthetic test and on the real regional gravimetric data as well. The results show the method could be useful step before the density modelling process and generally during qualitative interpretation in applied gravimetry.
\end{abstract}

Key words: gravimetry, fault, slope, curvature

\section{Introduction}

There are several model geometries used to approximate the interpreted density inhomogeneity in the quantitative interpretation of gravimetric data. Among them, the 2D inclined step plays an important role, while it satisfactorily describes sub-vertical density contacts of different tectonic units like transitions between mountain belts and adjacent sedimentary basins. There exist a huge variety of methods, which use this geometry for the modelling or the depth estimation of the density contact itself (e.g. Geldart et al., 1966; Chakravarthi, 2011; Essa, 2013; Abdelrahman et al., 2019).

One of the crucial steps in all methods connected with the inclined step, is the direct estimation of the slope without any geological constraints. There are several approaches, which try to solve this problem (Gupta and Pokhriyal, 1990; Abdelrahman et al., 2013 a.o.). In this contribution, we utilize the interesting properties of the gravitational effect's curvature. There

\footnotetext{
${ }^{*}$ corresponding author: e-mail: roland.karcol@uniba.sk
} 
are, already, several contributions, using the properties of the curvatures in the potential data interpretation (Schmidt and Götze, 2003; Phillips et al., 2007; Li and Cevallos, 2013; Cevallos et al., 2013; Li, 2015 a.o.), but based on our knowledge, none of them is focused on the inclined step's slope estimation problem. The first curvature of the gravitational effect of the inclined step model shows some interesting properties, which can be used for the recognition of the main character of the slope's sign. We present the results from a synthetic modelling (with artificial noise added) and the application of the presented method on some real datasets (acquired in the Western Carpathian region, some of them with geological constraints as a control of our results, too), as well.

We have to clarify the importance of the used terminology here. The terms "normal" and "reverse" fault (from the geological terminology point of view) are based on the orientation of the mechanical stress acting upon the rock formations and the corresponding way of their movement (e.g. Svoboda, 1983). This means, that both terms can be assigned to e.g. a slope with negative sign. Therefore, the geological assumptions related to e.g. density distribution within models/real situations, are necessary to the assignment of the correct term (fault's type) to the solved situation.

\section{Theory}

The model we are dealing with is based on the inclined step $-11 / 2$ body from the direct problem point of view. The gravitational attraction vector consists of $V_{z}$ component only:

$$
V_{z}(x, z)=2 \kappa \sigma\left[\begin{array}{c}
\zeta \arctan \frac{\zeta-k x-q}{k(\zeta-z)}-\frac{k(k x+q-z)}{2\left(k^{2}+1\right)} \times \\
\times \ln \left(k^{2}(\zeta-z)^{2}+(\zeta-k x-q)^{2}\right) \\
-\frac{k^{2} z+k x+q}{k^{2}+1} \arctan \frac{\zeta\left(k^{2}+1\right)-k^{2} z-k x-q}{k(k x+q-z)}+ \\
+\frac{\pi}{2}|\zeta-z|
\end{array}\right]_{\zeta_{1}}^{\zeta_{2}}
$$

here $k$ is the slope and $q$ is the absolute term of the line, which controls the inclination of the step, $z$ and $x$ are calculation point coordinates (positive 
part of vertical $(z)$ axis is oriented upwards), $\zeta_{1}$ and $\zeta_{2}$ are edges of the step in the vertical direction, $\sigma$ is the density (assumed to be a constant), $\kappa$ stands for the gravitational constant. Note that presented formula is valid only for the points located above the step, what is satisfactory for the objective of our task. The scheme of two basic options $(k<0 ; k>0)$ and corresponding fields are displayed on Fig. 1.

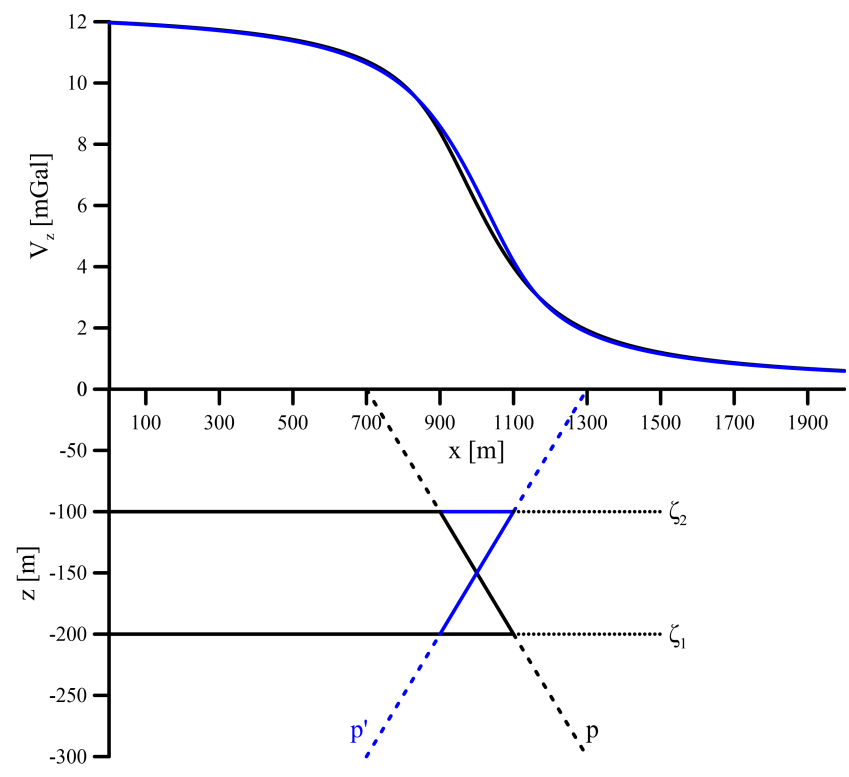

Fig. 1. The scheme of two basic types of an inclined step: negative slope line $p(k=-0.5$ - black) and positive slope line $p^{\prime}(k=0.5$ - blue) with corresponding gravitational effect $V_{z}$ calculated on the level $z=0 \mathrm{~m}$ (the geometrical parameters are clear from the figure, the density was $\sigma=3000 \mathrm{~kg} \mathrm{~m}^{-3}$ ).

The gravitational effect curves are very similar to each other in this particular case. So, the question is: how to distinguish between them, or how to set the correct sign of the slope? We will demonstrate the usage of the first curvature $K$ for the planar case $(z=f(x))$ given by (e.g. Rektorys, 1968, p. 260 or Thomas and Finney, 1996, p. 890):

$K=\left|\frac{f^{\prime \prime}(x)}{\left[1+\left(f^{\prime}(x)\right)^{2}\right]^{\frac{3}{2}}}\right|$. 
Next, the input data $f(x)$ will not be the calculated/measured gravitational field only, but its upward continuation, too. The idea behind this approach is that the change in the shape of resultant curvature with increasing height of upward calculation, could bring new information into discussed problem. The differentiation and upward continuation will be carried out in the Fourier domain, while they are represented by simple multiplications of spectra with corresponding spectral operators there. More, the differentiation is an unstable operation (e.g. Pašteka et al., 2009) on the contrary to the stable operation of the upward continuation. If the upward continued field is used as the input for the curvature's calculation, the instability caused by differentiations will be "covered" by stabilizing effect of upward continuation, because the differentiation is controlled by linear function (first order differentiation) or by quadratic function (second order differentiation) in the spectral domain, while the spectral characteristic of the upward continuation is the exponential function of the spectral variable. Finally, the operators for differentiation and continuation can be simply combined into single operation in the spectral domain.

The analytical solution (curvature curves) for the simple cases (displayed on Fig. 1) requires following formulae:

$$
\begin{aligned}
& \frac{\partial V_{z}}{\partial x}=-\frac{\kappa \sigma}{\left(k^{2}+1\right)}\left[2 k \arctan \frac{\zeta\left(k^{2}+1\right)-k^{2} z-k x-q}{k(k x+q-z)}+\right. \\
& \left.+k^{2} \ln \left(k^{2}(\zeta-z)^{2}+(\zeta-k x-q)^{2}\right)\right]_{\zeta_{1}}^{\zeta_{2}} \\
& \frac{\partial^{2} V_{z}}{\partial x^{2}}=-\frac{\kappa \sigma}{\left(k^{2}+1\right)}\left[\frac{k^{3}(k x+q+z-2 \zeta)}{\zeta^{2}\left(k^{2}+1\right)-2 \zeta\left(k x+q+k^{2} z\right)+(k x+q)^{2}+k^{2} z^{2}}\right]_{\zeta_{1}}^{\zeta_{2}} .
\end{aligned}
$$

The resultant (theoretical/analytical) curves of the first curvature are displayed on Fig. 2a (the negative slope (normal fault), black) and Fig. 2b (positive slope (reverse fault), blue).

The shape of these curves allows us to decide about the sign of the step's slope. The inflection point of the original input field curves (Fig. 1) is clearly recognized as a local minimum close to the centre of the curvature's curves - closer look shows that local minimum is shifted to the left from the $x=1000 \mathrm{~m}$ coordinate (the centre of the inclined side) for the negative slope (normal fault) or to the right from this coordinate for positive 


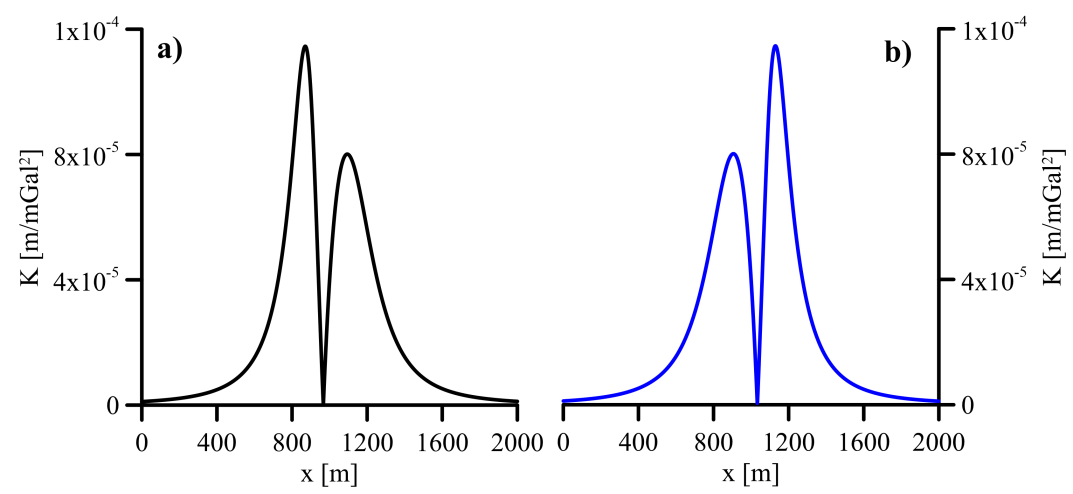

Fig. 2. The analytical curvature ( $K$, equation (2)) curves for the elementary models at level $z=0$ : a) negative slope b) positive slope.

slope (reverse fault). Next, the local maxima at these curves are related to the beginning and end of the inclined side of the step and the amplitude and position of them can reveal the information about the slope's sign, too. Next question could be: how will these properties look like for the more complex/real situations and for the upward continued inputs. The answer is clear from the direct problem attributes - the curvature curves will be more symmetrical (the difference in the amplitude of the local maxima will decrease) and the local minimum in the centre will move closer to the centre of the inclined side, as the input field is getting smoother and more symmetrical with increasing of the calculation height, see Fig. 3 for the $z=400 \mathrm{~m}$ as an example.

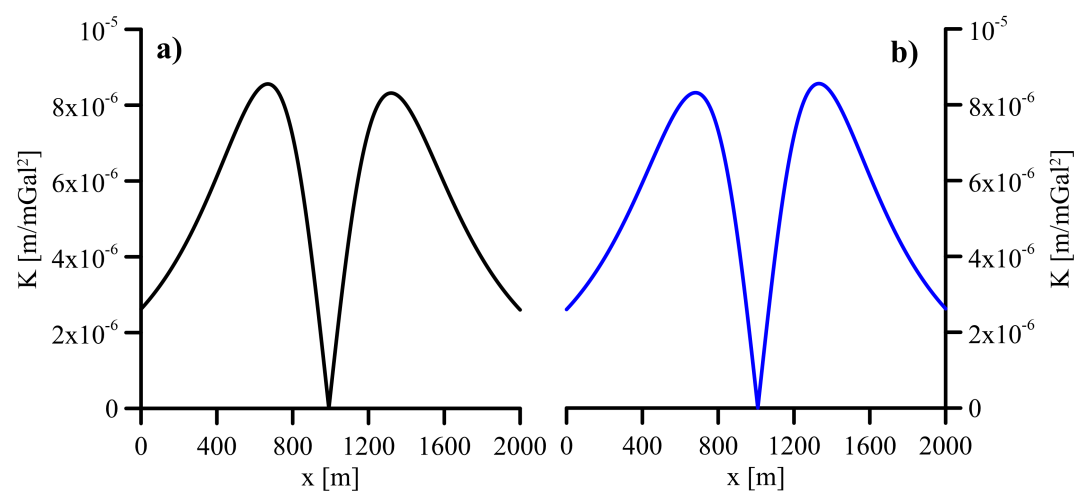

Fig. 3. The analytical curvature curves for elementary models at level $z=400 \mathrm{~m}$ for a) negative slope (normal fault), b) positive slope (reverse fault). 
So, the workflow will be as follows - the solutions for the several heights of the upward continuation will be obtained and the described changes in the shape of the resultant curves are used as criteria for setting of the slope's sign.

\section{Testing}

\subsection{Synthetic Test A}

Two basic models (negative and positive slope based) are created. The models consist of 3 blocks (A, B and C). We discuss two basic options of the density ratios: a) the B block's density is lower $\left(\sigma_{B}=2400 \mathrm{~kg} \mathrm{~m}^{-3}\right)$ than density of $\mathrm{A}$ and $\mathrm{C}$ blocks $\left(\sigma_{A}=\sigma_{C}=2700 \mathrm{~kg} \mathrm{~m}^{-3}\right)$ and b) the $\mathrm{B}$ block's density is higher $\left(\sigma_{B}=2700 \mathrm{~kg} \mathrm{~m}^{-3}\right)$ than density of $\mathrm{A}$ and $\mathrm{C}$ blocks $\left(\sigma_{A}=\sigma_{C}=2400 \mathrm{~kg} \mathrm{~m}^{-3}\right)$, see Fig. 4a and Fig. 4b for the schemes and gravitational effects (the geometrical parameters of the models are in the Table 1). The sampling step is $50 \mathrm{~m}$ on the profile of $6 \mathrm{~km}$ span. The input data are corrupted with the truncated Gaussian noise from the interval $\langle-0.005 ; 0.005\rangle \mathrm{mGal}$, i.e. the noise amplitude is $0.01 \mathrm{mGal}$, what is a resolution of the present field gravity meters. Next, the curvatures calculated for

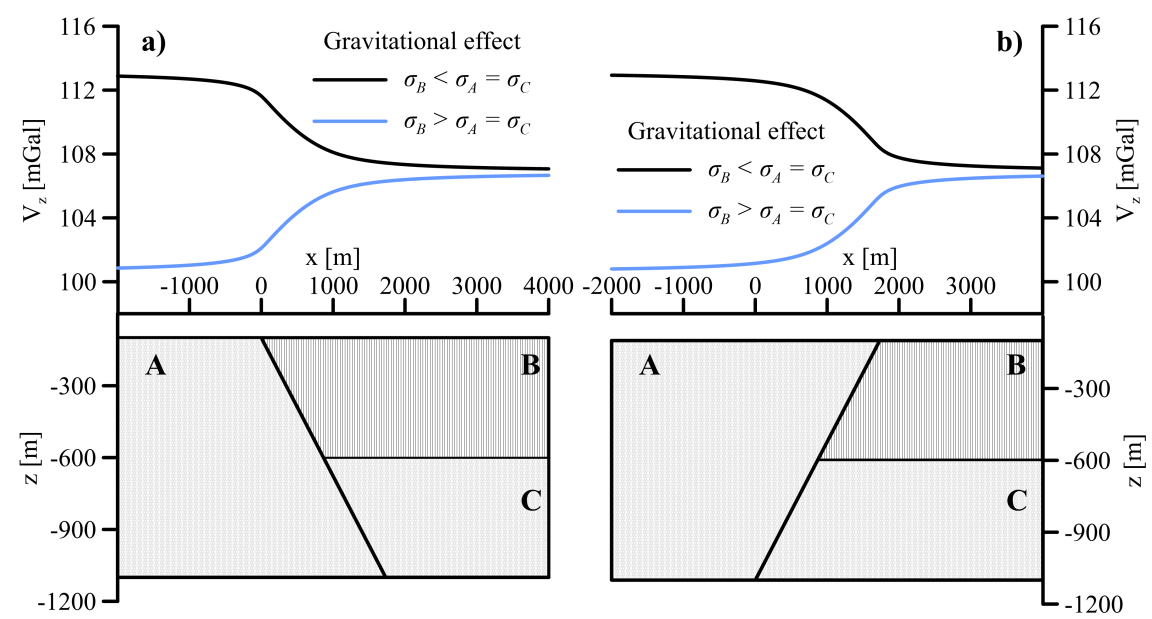

Fig. 4. The scheme of models (see Table 1 for parameters) and their gravitational effects for the Synthetic Test A (two options of density distribution), a) negative slope model, b) positive slope model. 
Table 1. The parameters of the models for synthetic test $\left(\zeta_{1}\right.$ and $\zeta_{2}$ are limits in the vertical direction).

\begin{tabular}{|c|c|c|c|c|}
\hline Body & $\zeta_{1}[\mathrm{~m}]$ & $\zeta_{2}[\mathrm{~m}]$ & positive slope line $p$ & negative slope line $p$ \\
\hline A & -1100 & -100 & \multirow{2}{*}{$p: z=-\frac{\sqrt{3}}{3} x-100$} & \multirow{2}{*}{$p: z=\frac{\sqrt{3}}{3} x-1100$} \\
\cline { 1 - 3 } B & -600 & -100 & & \\
\hline C & -1100 & -600 & & \\
\hline
\end{tabular}

a several heights of upward continuation, will be normalized to the number one for a better comparison, while we are interested in the shape of them not the real amplitudes.

The surface solutions for both models and density distribution are displayed on the Fig. 5a and 5b, the solutions for the set of upward continued inputs are displayed on Fig. $5 \mathrm{c}$ and $5 \mathrm{~d}$.
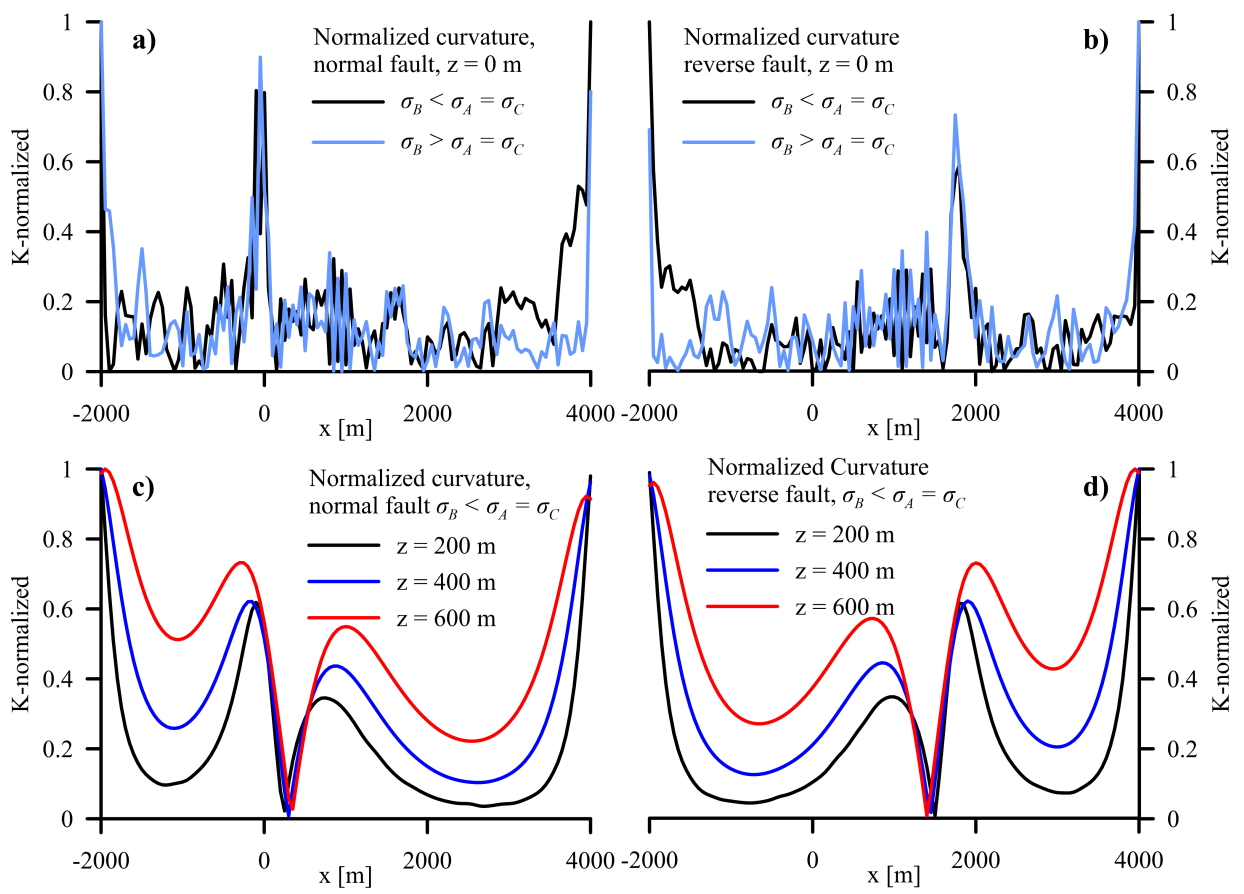

Fig. 5. T The normalized curvatures ( $K$-normalized) for the Synthetic Test A, two options of the density distribution: a) the surface solution for a negative slope, b) the surface solution for a positive slope, c) the solutions for upward continued inputs, negative slope, d) the solutions for upward continued inputs, positive slope. 
There are expected features on the surface solutions (Fig. 5a,b): the results are disturbed, the lower of the local maxima is not developed well - it is corrupted by an amplified noise (during the numerical calculation of derivatives, entering into eq. (2)). The edge effects (unwanted but necessary products of data manipulation within a spectral domain) are of higher amplitudes than the central part we are interested in - that is why the side parts of the results do not tend to zero, as they should. This occur for rest of the solutions (Fig. 5c, d), too. This could be partly fixed if the normalization is carried out after the side effects cutting-off. The left-right side shift and amplitudes changes of the local extrema are clearly visible for solutions obtained for the set of upward continuation heights, and so, reveal the sign of the slope satisfactory. The one of the important properties of the presented normalized curvatures is not displayed at all - the solutions for the second density distribution $\sigma_{B}>\sigma_{A}=\sigma_{C}$ are the same (indistinguishable) as the solutions for $\sigma_{B}<\sigma_{A}=\sigma_{C}$, for both slope's signs. This means, that not only the sign of the slope could be revealed, but the density's ratio could be discussed, too.

\subsection{Synthetic Test B}

The more complicated rift valley model is sprepared for the second synthetic test, where each inclined step is of the different slope with the $50 \mathrm{~m}$ sampling step on the profile of $10 \mathrm{~km}$ profile span, the density of the layers from the surface to the bottom are: $\sigma_{1}=$ $2400 \mathrm{~kg} \mathrm{~m}^{-3}, \sigma_{2}=2600 \mathrm{~kg} \mathrm{~m}^{-3}, \sigma_{3}=$ $2750 \mathrm{~kg} \mathrm{~m}^{-3}$ (Fig. 6).

The truncated Gaussian noise from the interval $\langle-0.04 ; 0.04\rangle \mathrm{mGal}$, i.e. the noise amplitude is $0.08 \mathrm{mGal}$, what is about $4.2 \%$ of the input field amplitude. The solutions are displayed on Fig. 7 and each solution is compared to the

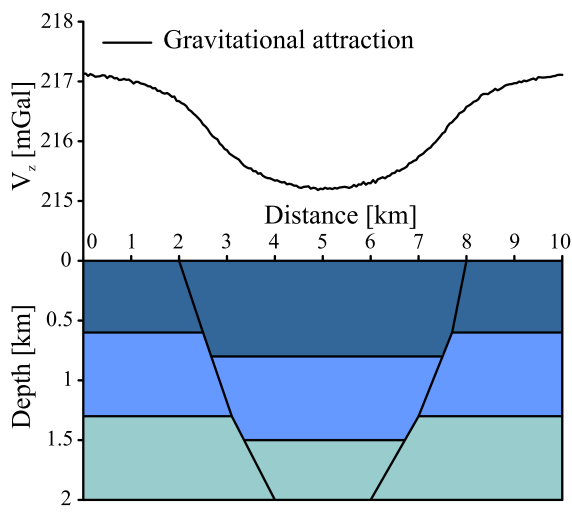

Fig. 6. The 3-layered rift valley model for the synthetic test B with the input field ( $V_{z}-$ gravitational effect). result for the noise-free input. 

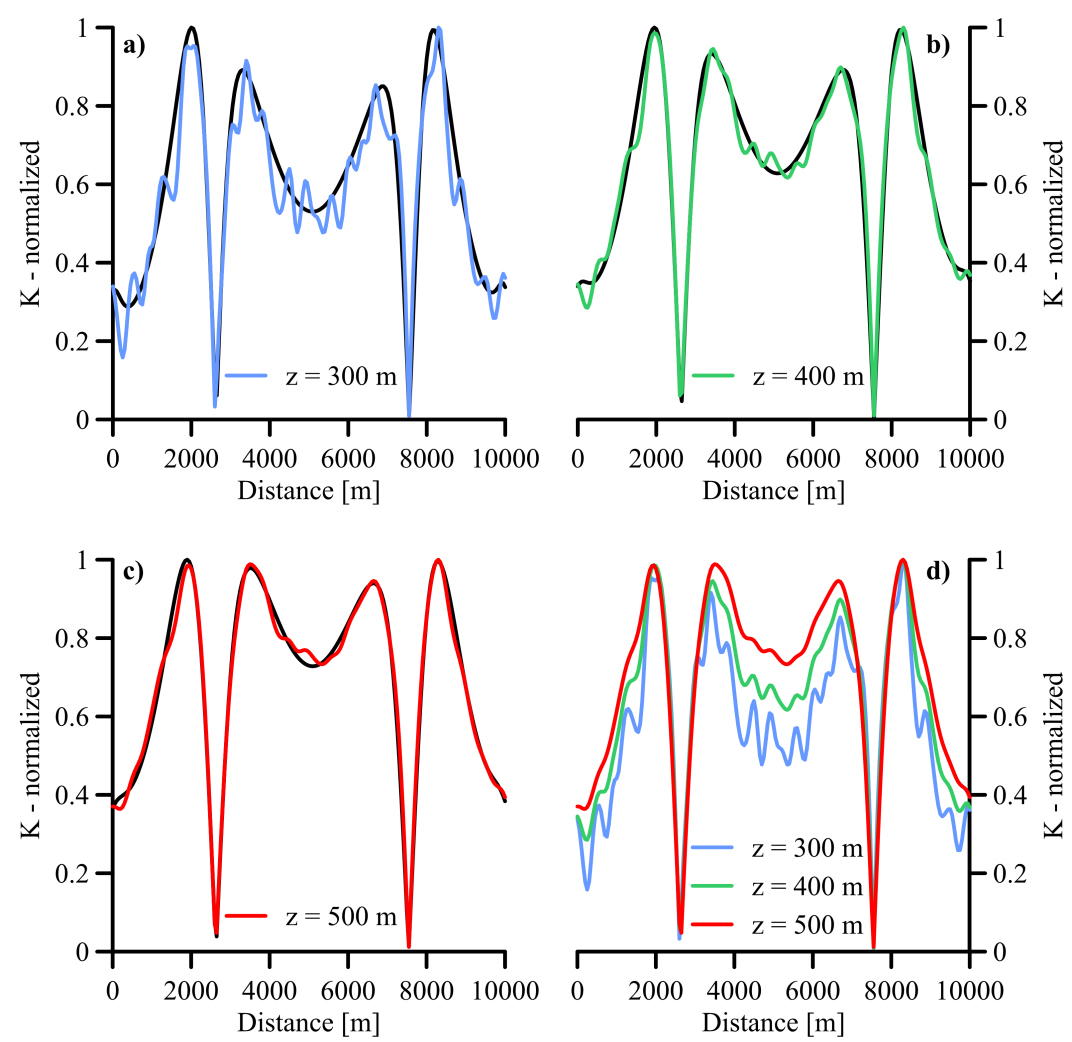

Fig. 7. The normalized curvatures for the several heights $(z)$ of the upward continuation for the Synthetic Test B: a) $z=300 \mathrm{~m}$ (blue), solution for the noise-free input (black), b) $z=400 \mathrm{~m}$ (green), solution for the noise-free input (black), c) $z=500 \mathrm{~m}$ (red), solution for the noise-free input (black), d) the combination of the solutions for the set of upward continuation heights: $z=300 \mathrm{~m}$ (blue), $z=400 \mathrm{~m}$ (green), $z=500 \mathrm{~m}$ (red).

The local minima are not shifting to the side significantly with the increasing of the recalculation height. This is caused by larger sampling step. However, the evaluation of the two pairs of local maxima is able to identify the sign of the slope. Precisely, the local maxima's amplitudes of the sinistral pair are in the ratio as described on Fig. 2a or Fig. 5c (the left one is higher than right one), and vice-versa for the dextral pair of local maxima. Here, the satisfactory conclusion about slope sign is available for each height of recalculation. However, the balance between solution's noise level and details in the curvature's curve is the most acceptable for $z=400 \mathrm{~m}$ 
according to our opinion. For this height, the desired features in the curve shape are still well visible and noise level is low enough already.

\subsection{Real data Test A}

The input field is the detailed gravimetry profile running from the CentralCarphatian Paleogene (CCP) formations into Pieniny Klippen Belt (PKB) located close vicinity of Jarabina village near Stara Lubovna, NE Slovakia (Plašienka, 2018), see Fig. 8 for a location within Slovakia, detailed Bouguer
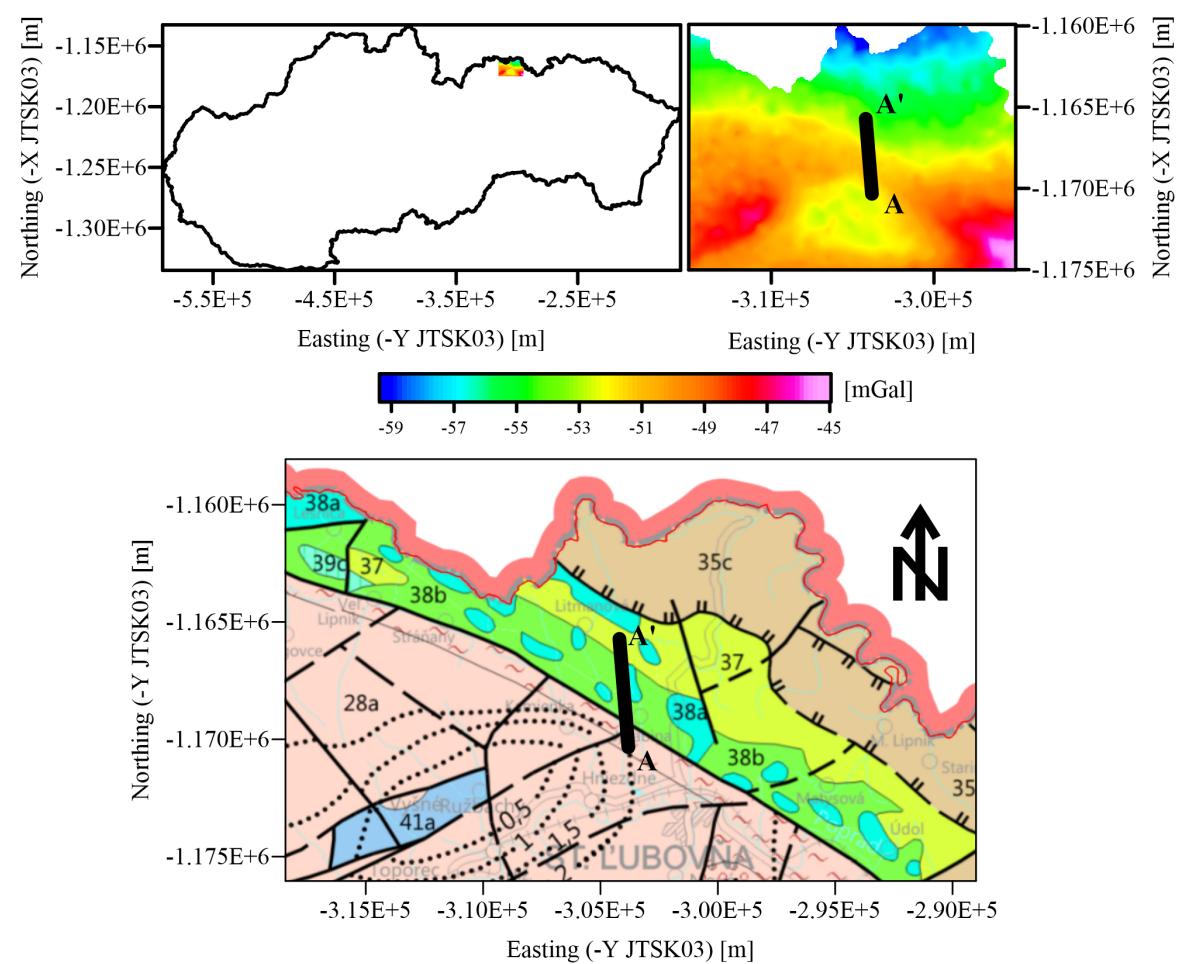

Fig. 8. The maps for the Real data Test A: top-left: a position of the studied area within Slovakia; top-right: a detailed complete Bouguer anomaly map with highlighted position of interpretation profile (thick black line); bottom: a selected part from the tectonic map of Slovak Republic (modified from Bezák et al., 2004) with the position of the interpretation profile (thick black line). Selected codes from the legend of the tectonic map: 28a - deep water sediments (Middle Eocene - Early Miocene age), 38a - isolated klippes, carbonates (Jurassic - Lower Cretaceous complexes), 38b - sediments (Middle - Upper Cretaceous complexes), 35c - flysh sediments (Oravská Magura nappe, Oligocene age). 
anomaly map with position of the interpretation profile, and a geological map with tectonic structures in the studied site. The detailed gravimetric measurements have been realised along a line crossing the CCP-PKP contact with an acquistion step $20 \mathrm{~m}$ (Mikuš, 2008) - we use the southern part of the profile highlighted on the Fig. 8, where it "hits" the contact between $\mathrm{CCP}$ and PKB. The geological assumption says, that KB (higher density) is slightly shifted over the CCP (lower density) (a reverse fault (?)), what is situation described at Fig. 4a, blue line (negative slope, with $\sigma_{B}>\sigma_{A}=$ $\left.\sigma_{C}\right)$. The data are highly corrupted by the noise/effects of the shallow sources and measurement errors, see Fig. 9a. We decide to cut-off the side effects and carry out the normalization after that, too. The results are displayed on Fig. 9b.
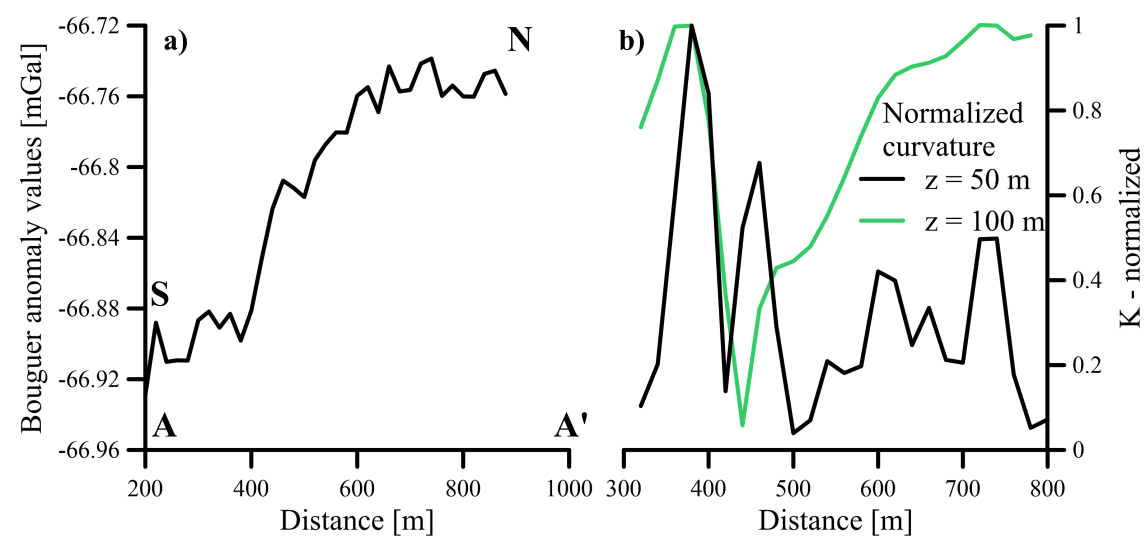

Fig. 9. The Real data Test A: a) the input field (Bouguer anomaly values), $\mathrm{S}$ and $\mathrm{N}$ stands for cardinal points, b) the normalized curvature (after side effect's cut-off) for two heights of the upward continuation $\left(z_{1}=50 \mathrm{~m}, z_{2}=100 \mathrm{~m}\right)$.

The first solution ( $z=50 \mathrm{~m}$, Fig. 9a, black curve) shows the desired pattern clearly - two local maxima and local minimum in close vicinity of the assumed position of the inflection point of the input field's curve. According to this, our statement is that this situation is in an agreement with the upper mentioned geological suggestion. The situation around the second solution $(z=100 \mathrm{~m})$ is not that clear - the second local maximum is almost erased by side effects, despite the fact, that the strongest one was cut-off. However, if compared to the first solution, the indication of second local maximum is visible/deductive. Therefore, the successful interpretation 
requires the set of upward continuation levels. According to the presented results and geological assumptions, we can discreetly deduce about reverse fault in this site.

\subsection{Real data Test B}

We are studying the contact between Malé Karpaty Mts. and the sedimentary filling of Danube Basin in its western part (SW Slovakia) in the Western Carphatians region (Kytková et al., 2007). The geological suggestions
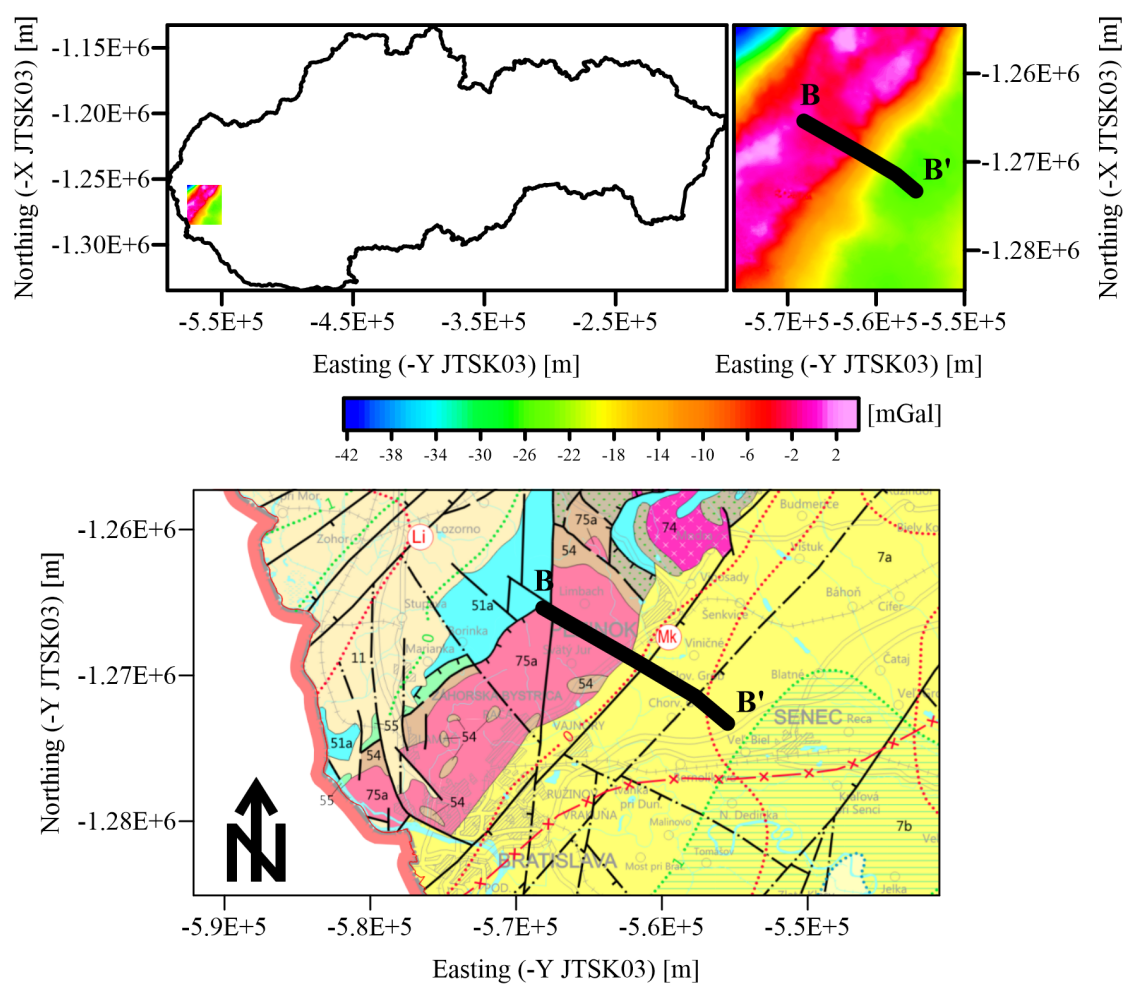

Fig. 10. The maps for the Real data Test B: top-left: a position of the studied area within Slovakia; top-right: a detailed complete Bouguer anomaly map with highlighted position of interpretation profile (thick black line); bottom: a selected part from the tectonic map of Slovak Republic (modified from Bezák et al., 2004) with the position of the interpretation profile (thick black line). Selected codes from the legend of the tectonic map: 75a - granodiorites and granites (Devonian and Lowe Carboniferous age), 7a synrift sediments (Badenian - Sarmatian age). 
shows negative slope related to the extension in the area (normal fault), and the density distribution as described in Fig. 4a, black curve (the densities of cristalline rocks in the Malé Karpaty Mts. are much higher than those of the sedimentary rocks in the Danube basin). The input data are taken/interpolated from the map of the complete Bouguer anomaly values for the correction density $2670 \mathrm{~kg} \mathrm{~m}^{-3}$ (Zahorec et al., 2017) (Fig. 10) and cubic splines were used to obtain regulary spaced data $(100 \mathrm{~m}$ sampling step), see Fig. 11a, for the input data. The results for the set of upward continuation's heights (normalized after strongest side-effects cut-off) are displayed on Fig. 11b.
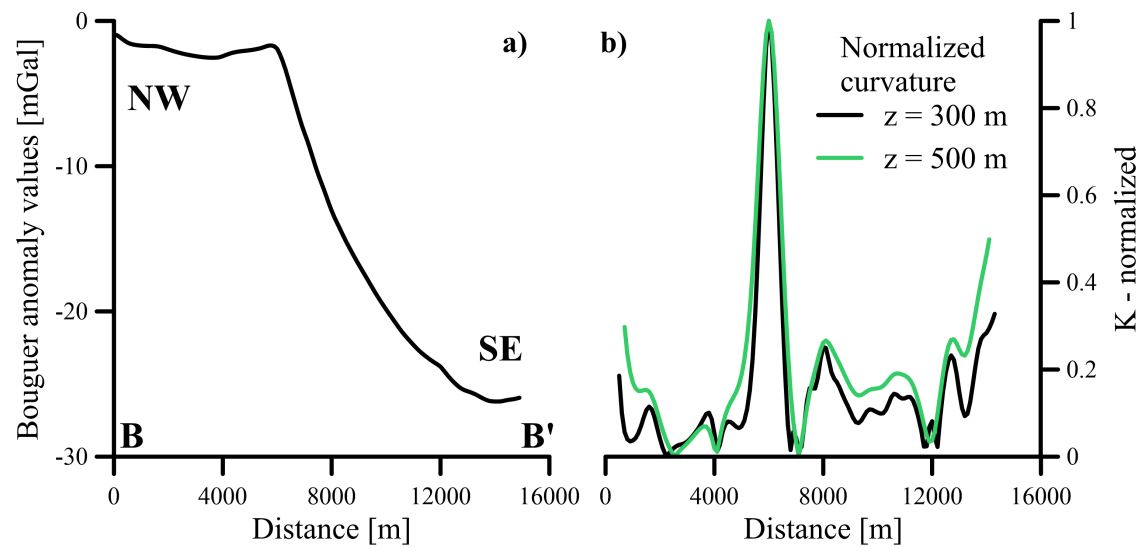

Fig. 11. The Real data Test B: a) the input field (interpolation of Bouguer anomaly values), NW and SE stands for cardinal points, b) the normalized curvature (after side effect's cut-off) for two heights of the upward continuation $\left(z_{1}=300 \mathrm{~m}, z_{2}=500 \mathrm{~m}\right)$.

Again, the results are in the coindicence with the geologic assumption, i.e. the negative slope with density distribution as described on the Fig. 4a, black line (negative slope, with $\sigma_{B}<\sigma_{A}=\sigma_{C}$ ). These results can be understand as another arguments for the extension nature of the discussed site.

\section{Conclusion}

The problem of the slope sign could be prior to the 2D density modelling process. The gravitational effects of the discussed situations (positive or negative slope's sign) are very close to each other. The deciding property of 
the calculated curvature's curves are the positions and relative amplitudes of local maxima - the higher of the local maxima pair is related to the edge of the slope closer to the surface/measuring profile, the lower one is related to the bottom edge of the slope. Their succession reveals the orientation (a sign) of the slope: the negative slope is described by higherlower order of local maxima, and vice-versa for the positive slope. More, local minimum (which separates the local maxima pair) and the change of its position is helpful, too. The final decision about fault's type requires the geological information, too. The curvature seems to be the deciding tool as we demonstrated on the synthetic and real data sets tests. Such curvature test is simple and fast. However, the upward continuation seems to be very important step in this procedure, because of its stabilization effect and controlling of the changes in the curvature's curves shape. The processing in the spectral domain brings the side-effect problem into discussion, but again, the upward continued inputs were successful in lowering this problem, too. Future work would be focused on next tests in typical sites with faults contact, and on the setting of the slope's size, as well.

Acknowledgements. This work was supported by the projects of the Scientific and Grant Agency of Slovak Republic VEGA 2/0100/20, APVV-16-0146 and APVV-190150.

\section{References}

Abdelrahman E. M., Essa K. S., Abo-Ezz E. R., 2013: A least-squares window curves method to interpret gravity data due to dipping faults. J. Geophys. Eng., 10, 2, 025003, doi : 10.1088/1742-2132/10/2/025003.

Abdelrahman E. M., Gobashy M., Abo-Ezz E. R., El-Araby T., 2019: A new method for complete quantitative interpretation of gravity data due to dipping faults. Contrib. Geophys. Geod., 49, 2, 133-151, doi : 10.2478/congeo-2019-0007.

Bezák V. (Ed.), Broska I., Ivanička J., Reichwalder P., Vozár J., Polák M., Havrila M., Mello J., Biely A., Plašienka D., Potfaj M., Konečný V., Lexa J., Kaličiak M., Žec B., Vass D., Elečko M., Janočko J., Pereszlényi M., Marko M., Maglay J., Pristaš J., 2004: Tectonic map of the Slovak Republic, scale 1:500 000. State Geological Institute of Dionýz Štúr, Bratislava, Slovakia.

Cevallos C., Kovac P., Lowe S. J., 2013: Application of curvatures to airborne gravity gradient data in oil exploration. Geophysics, 78, 4, G81-G88, doi : 10.1190/geo20120315.1.

Chakravarthi V., 2011: Automatic gravity optimization of 2.5D strike listric fault sources with analytically defined fault planes and depth-dependent density. Geophysics, 76 , 
2, I21-I31, doi: 10.1190/1.3541957.

Essa K. S., 2013: Gravity interpretation of dipping faults using the variance analysis method. J. Geophys. Eng., 10, 1, 015003, doi : 10.1088/1742-2132/10/1/015003.

Geldart L. P., Gill D. E., Sharma B., 1966: Gravity anomalies of two-dimensional faults. Geophysics, 31, 2, 372-397, doi: 10.1190/1.1439781.

Gupta O. P., Pokhriyal S. K., 1990: New formula for determining the dip angle of a fault from gravity data. SEG Technical Program Expanded Abstract, 9, 646-649, doi: $10.1190 / 1.1890290$.

Kytková B., Tomek C., Bielik M., Putiš M., 2007: Interpretation of deep seismic reflection profiles in the northern part of the Malé Karpaty Mountains. Contrib. Geophys. Geod., 37, 1, 43-58.

Li X., 2015: Curvature of a geometric surface and curvature of gravity and magnetic anomalies. Geophysics, 80, 1, G15-G26, doi: 10.1190/geo2014-0108.1.

Li X., Cevallos C., 2013: Curvature of the equipotential surface, gravity potential, field and gradient anomalies. 83rd Annual International Meeting, SEG Technical Program Expanded Abstracts, 1180-1184, doi: 10.1190/segam2013-0379.1.

Mikuš V., 2008: Interpretation of the detail profile gravity measurements in the scope of the Pieniny Klippen Belt (locality Jarabina). M.Sc.-thesis, Comenius University in Bratislava, Faculty of Natural Sciences, Department of applied and environmental geophysics, Manuscript, $50 \mathrm{p}$.

Phillips J. D., Hansen R. O., Blakely R. J., 2007: The use of curvature in potential-field interpretation. Explor. Geophys., 38, 111-119, doi: 10.1071/EG07014.

Pašteka R., Richter F. P., Karcol R., Brazda K., Hajach M., 2009: Regularized derivatives of potential fields and their role in semi-automated interpretation methods. Geophys. Prospect., 57, 507-516, doi: 10.1111/j.1365-2478.2008.00780.x.

Plašienka D., 2018: The Carpathian Klippen Belt and types of its klippen - an attempt at a genetic classification. Miner. Slovaca, 50, 1, 1-24.

Rektorys K., 1968: The compendium of applied mathematics. SNTL - Publishing House of Technical Literature, Prague (in Czech).

Schmidt S., Götze H.-J., 2003: Pre-interpretation of potential fields by aid of curvature attributes. A poster presentation at European Geophysical Society Annual Meeting, Nice, France, 6-11 April 2003.

Svoboda J., 1983: Encyklopedický slovník geologickch věd, Academia, Praha, 916 p. (in Czech).

Thomas G. B., Finney R. L., 1996: Calculus and Analytic Geometry, 9th ed. AddisonWesley Publishing Company, 1264 p.

Zahorec P., Pašteka R., Mikuška J., Szalaiová V., Papčo J., Kušnirák D., Pánisová J., Krajňák M., Vajda P., Bielik M., Marušiak I., 2017: Chapter 7 - National Gravimetric Database of the Slovak Republic. In: Pašteka R., Mikuška J., Meurers B. (Eds.): Understanding the Bouguer Anomaly: A Gravimetry Puzzle. Elsevier, Amsterdam, 113-125, doi: 10.1016/B978-0-12-812913-5.00006-3. 